\title{
Research Article \\ Effect of Glazing on Flexural Strength of Full-Contour Zirconia
}

\author{
Hattanas Kumchai (D), Patrapan Juntavee, Arthur F. Sun, and Dan Nathanson \\ Department of Restorative Sciences \& Biomaterials, Boston University Henry M. Goldman School of Dental Medicine, Boston, \\ MA, USA \\ Correspondence should be addressed to Hattanas Kumchai; hattanas@bu.edu
}

Received 8 September 2017; Revised 14 December 2017; Accepted 27 December 2017; Published 5 February 2018

Academic Editor: Carlos A. Munoz-Viveros

Copyright (c) 2018 Hattanas Kumchai et al. This is an open access article distributed under the Creative Commons Attribution License, which permits unrestricted use, distribution, and reproduction in any medium, provided the original work is properly cited.

\begin{abstract}
Objective. The purpose of this study was to evaluate the effect of glazing on flexural strength of highly translucent zirconia materials. Materials and Methods. Specimens of three brands of zirconia bars (Prettau Zirconia, Zirkonzahn; inCoris TZI, Sirona; and Zirlux FC, Pentron Ceramics) were prepared and polished according to manufacturers' instructions. Final specimen dimensions were $20 \times 4 \times 2 \mathrm{~mm}$. The specimens from each brand were divided into 3 groups $(N=10)$ : control, heat-treated, and glazed. Heat-treated specimens were fired without the application of the glaze material. The glaze material was applied to the glazed specimens before being fired. A three-point bending test $(15 \mathrm{~mm}$ span) was performed in an Instron universal testing machine (ISO 6872). Data were analyzed by ANOVA and Tukey's HSD post hoc test $(\alpha=0.05)$. Results. Two-way ANOVA showed a significant influence of surface treatments on flexural strength of zirconia materials $(P \leq 0.05)$. There was no significant difference in flexural strength among the different brands of highly translucent zirconia $(P \geq 0.05)$. Tukey's HSD post hoc test showed that specimens in the "glazed" group had significantly lower flexural strength than the control and heat-treated groups $(P \leq 0.05)$. Conclusion. Within the limitations of the study, external glazing decreased the flexural strength of highly translucent zirconia.
\end{abstract}

\section{Introduction}

The glazing of porcelain dental restorations is a routine procedure designed to provide esthetic and hygienic glasscoated surfaces on the finished restoration $[1,2]$. Applied overglaze is a low-fusing clear porcelain that is painted onto the surface of the restoration and fired at a fusing temperature much lower than that of the dentin and enamel porcelain [3]. Glazing for the purpose of strengthening brittle ceramics can be considered the production of a surface layer of lower thermal expansion glass that serves many functions when cooled. It places the surface in a compressive state. The thin layer of glass also reduces the depth and width of surface flaws and could theoretically strengthen the material [4]. Glazed surfaces result in less plaque accumulation. In addition, glazed porcelain can imitate the gloss and characterization of the natural tooth [5]. It decreases the exposure of the dental restoration to the oral cavity and provides the necessary smoothness [2].

However, many studies have shown that glazing does not increase flexural strength $[1,4,6]$. It has also been shown that autoglazing does not cause a difference in the flexural strength of porcelain specimens $[1,4,6]$. Although glazing reduces the wear of opposing enamel, it was found that glazing causes cracks in the porcelain and thus decreases flexural strength [4]. Yener et al. [7] compared the biaxial flexural strength of three different brands of zirconia (Zirkonzahn, Cercon, and Ceramill) with and without glazing. Their results showed that glazing significantly decreased the flexural strength for all systems.

The introduction of highly translucent yttrium oxidestabilized tetragonal zirconia polycrystals (Y-TZPs) enabled the esthetics of monolithic zirconia restorations to be sufficiently improved. The high translucency of the Y-TZP was achievable by decreased alumina content [8], which is normally incorporated into zirconia materials to increase their stability during aging yet causes light scattering due to a refractive index different from that of zirconia. Reduction or elimination of alumina content in zirconia materials makes them vulnerable to problems with stability during aging [9].

Although many clinicians prefer to glaze monolithic zirconia restorations, data regarding the effect of glazing on 
the mechanical properties of these materials are still lacking. The purpose of this study was to evaluate the effect of glazing on the flexural strength of highly translucent zirconia materials. The study examined the flexural strength of three different brands of translucent zirconia with different surface treatments.

\section{Materials and Methods}

Three different brands of zirconia and two different glaze materials (Table 1) were tested in this study. In total, 10 rectangular specimens of zirconia for each group were prepared (dimensions, $2.5 \times 5 \times 25 \mathrm{~mm}$ ) by means of a $15 \mathrm{LC}$ diamond-wafering blade mounted on an Isomet 2000 precision saw (Buehler, Lake Bluff, Illinois, USA). The cuts were made at $800 \mathrm{rpm}$ with a 300 -gram load, with cooling provided by a dual-nozzle water irrigation system. Specimen dimensions were verified after they were sectioned by means of a Mitutoyo absolute IP-67 digital vernier caliper (Mitutoyo, Kawasaki, Japan).

Each specimen was polished and beveled $\left(45^{\circ}, 0.15 \mathrm{~mm}\right.$ edge chamfer) in a Buehler Ecomet 250 grinder/polisher (Buehler, Lake Bluff, Illinois, USA). The polishing was then done with a 15-micron grit diamond polishing pad at $30 \mathrm{rpm}$ with water irrigation for $90 \mathrm{~s}$ for each side, after which the specimen was rinsed thoroughly. For beveling, the specimen was placed at $45^{\circ}$ on a 15 -micron grit diamond polishing pad at $30 \mathrm{rpm}$ with water irrigation. The specimen was inspected for the presence of chamfer edge after the beveling. All specimens were air-dried at room temperature for at least $24 \mathrm{~h}$ to minimize the possibility of water being trapped in the zirconia structure. The sectioned bars were sintered with the parameters as in Table 2.

After being sintered, the specimens were polished again in a Buehler Ecomet 250 grinder/polisher (Buehler, Lake Bluff, Illinois, USA). The polishing was accomplished with a 15-micron grit diamond polishing pad, followed by a $6 \mu \mathrm{m}$ polycrystalline diamond suspension with a polishing pad, respectively, at $30 \mathrm{rpm}$ with water irrigation $(90 \mathrm{~s}$ for each side), and then thoroughly rinsed. The dimensions of the bars after being sintered and polished were approximately $20 \times 4 \times 2 \mathrm{~mm}$ according to ISO 6872:2015.

Specimens were divided into different groups according to surface treatments: (a) no treatment, (b) heat-treated, and (c) glazed.

2.1. Heat-Treated Firing. Zirconia specimens were air-dried and placed on a firing tray. They were then fired with the glaze firing cycle but without glaze materials. The firing parameters are shown in Table 3.

2.2. Glazing. Zirconia specimens were air-dried. The overglaze pastes were mixed with glaze liquids and applied in a thin coat on the entire surface of each zirconia bar using a ceramic brush. For Prettau Zirconia and inCoris TZI specimens, Zirkonzahn glaze paste and Zirkonzahn ICE stain liquid were used. For Zirlux FC specimens, Zirlux FC glaze paste and universal liquid were used. The glazing group
TABLE 1: Materials used in this study.

\begin{tabular}{lc}
\hline Material & Brand name \\
\hline \multirow{3}{*}{ Zirconia } & inCoris TZI (Sirona, Germany) \\
& Prettau Zirconia (Zirkonzahn, Germany) \\
& Zirlux FC (Pentron Ceramics, California) \\
Glaze & Zirkonzahn glaze paste + liquid (Zirkonzahn, Germany) \\
& Zirlux FC glaze paste + liquid (Pentron Ceramics, \\
California)
\end{tabular}

specimens were then placed on a firing tray. Glaze firing was done according to manufacturers' instructions (Table 4).

All specimens were then stored in $37^{\circ} \mathrm{C}$ deionized water for $24 \mathrm{~h}$ before testing began. Specimens were tested for flexural strength on a three-point bending test conducted on an Instron $5566 \mathrm{~A}$ universal testing machine (Instron, Norwood, Massachusetts, USA) with a $1 \mathrm{kN}$ load cell at a crosshead speed of $0.5 \mathrm{~mm} / \mathrm{min}$. Each specimen was loaded to failure and failure load data was obtained. The data were then calculated into flexural strength according to the following formula:

$$
\sigma=\frac{3 F L}{2 b d^{2}}
$$

where $F$ is the failure load (force) at the fracture point $(N)$, $L$ is the length of the support span, $b$ is the width, and $d$ is the thickness.

Statistical analysis was performed by means of SPSS System 23 for Windows. The means of each group were analyzed by two-way ANOVA, with flexural strength as the dependent variable and the zirconia systems and surface treatments as the independent factors. $P$ values less than 0.05 were considered statistically significant in all tests. Data from all zirconia brands were pooled, and multiple comparisons between and among different surface treatments were evaluated by Tukey's HSD test.

\section{Results}

The flexural strength data obtained from the three-point bending tests are presented in Table 5, Figures 1 and 2. The results of two-way ANOVA showed the significant influence of surface treatments on flexural strength $(P<0.05)$. The Tukey HSD post hoc test showed that specimens in the glazed group had significantly lower flexural strength than did those in the control and heat-treated groups $(P<0.05)$. There was no significant difference in flexural strength between specimens in the control and heat-treated groups $(P>0.05)$. There was no significant influence of zirconia brands on flexural strength $(P>0.05)$.

\section{Discussion}

Glazing after grinding is believed to increase the strength of a ceramic restoration because it decreases the depths of surface cracks [4]. However, the strengthening effect of glazing on porcelain is not clearly understood $[4,10]$.

In this study, for investigation of the effect of glaze on the flexural strength of three different highly translucent zirconia systems, Prettau Zirconia, inCoris TZI, and Zirlux FC were 
TABLE 2: Firing parameters for zirconia sintering.

\begin{tabular}{lcccc}
\hline Material & Entry temperature $\left({ }^{\circ} \mathrm{C}\right)$ & Rising temperature rate $\left({ }^{\circ} \mathrm{C}\right)$ & Final temperature $\left({ }^{\circ} \mathrm{C}\right)$ & Holding time $(\mathrm{min})$ \\
\hline inCoris TZI & Room temperature & 25 & 1530 & 120 \\
Prettau Zirconia & Room temperature & 10 & 1600 & 120 \\
Zirlux FC & Room temperature & 10 & 1500 & 120 \\
\hline
\end{tabular}

TABLE 3: Firing steps for heat-treated firing.

\begin{tabular}{|c|c|c|c|c|c|c|c|}
\hline Brand & Idle temp. $\left({ }^{\circ} \mathrm{C}\right)$ & Dry time (s) & End temp. $\left({ }^{\circ} \mathrm{C}\right)$ & Holding time $(\mathrm{min})$ & Heat rate $\left({ }^{\circ} \mathrm{C} / \mathrm{min}\right)$ & Vacuum & Tray open $\left({ }^{\circ} \mathrm{C}\right)$ \\
\hline Prettau Zirconia & 350 & 5 & 820 & 2 & 55 & + & - \\
\hline inCoris TZI & 350 & 5 & 820 & 2 & 55 & + & - \\
\hline Zirlux FC & - & 360 & 1000 & 0 & 55 & + & 480 \\
\hline
\end{tabular}

TABLe 4: Firing steps for glazed firing.

\begin{tabular}{lccccccc}
\hline Glaze material & Idle temp. $\left({ }^{\circ} \mathrm{C}\right)$ & Dry time $(\mathrm{s})$ & End temp. $\left({ }^{\circ} \mathrm{C}\right)$ & Holding time $(\mathrm{min})$ & Heat rate $\left({ }^{\circ} \mathrm{C} / \mathrm{min}\right)$ & Vacuum & Tray open $\left({ }^{\circ} \mathrm{C}\right)$ \\
\hline Prettau Zirconia glaze & 350 & 5 & 820 & 2 & 55 & + \\
Zirlux FC glaze & - & 6 & 1000 & 0 & 55 & + \\
\hline
\end{tabular}

TABLE 5: Flexural strength of highly translucent zirconia with different surface treatments.

\begin{tabular}{lccr}
\hline \multirow{2}{*}{ Zirconia } & \multicolumn{3}{c}{ Flexural strength (MPa) \pm standard deviation } \\
& Control & Heat-treated & Glazed \\
\hline inCoris TZI & $970.17 \pm 213.55$ & $1148.86 \pm 224.45$ & $800.88 \pm 117.12$ \\
Prettau Zirconia & $1005.12 \pm 180.85$ & $1037.80 \pm 82.81$ & $815.00 \pm 63.78$ \\
Zirlux FC & $1017.36 \pm 148.69$ & $911.03 \pm 127.67$ & $853.62 \pm 98.55$ \\
\hline
\end{tabular}

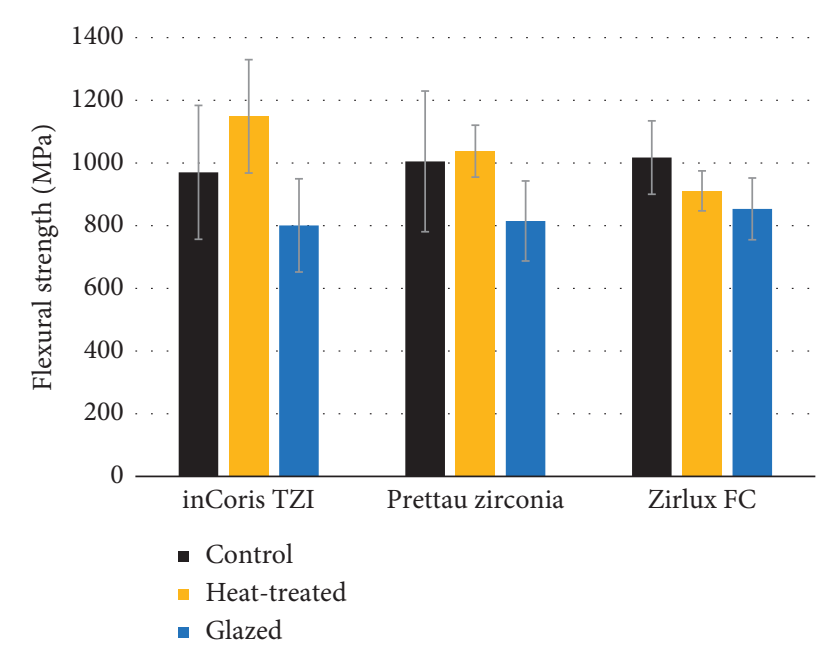

FIGURE 1: Flexural strength of highly translucent zirconia with different surface treatments.

used. Glazes were applied according to the manufacturer's recommendations for each system. It has been reported that $0.05 \mathrm{~mm}$ glaze thickness is sufficient to prolong its integrity [11]. Therefore, a $0.05 \mathrm{~mm}$ thickness of glaze was applied to each surface (a total of $0.1 \mathrm{~mm}$ ) of bar-shaped specimens.

Statistical analysis showed that glazing decreased the flexural strength of the highly translucent zirconia. This finding was supported by the results from another study [7],

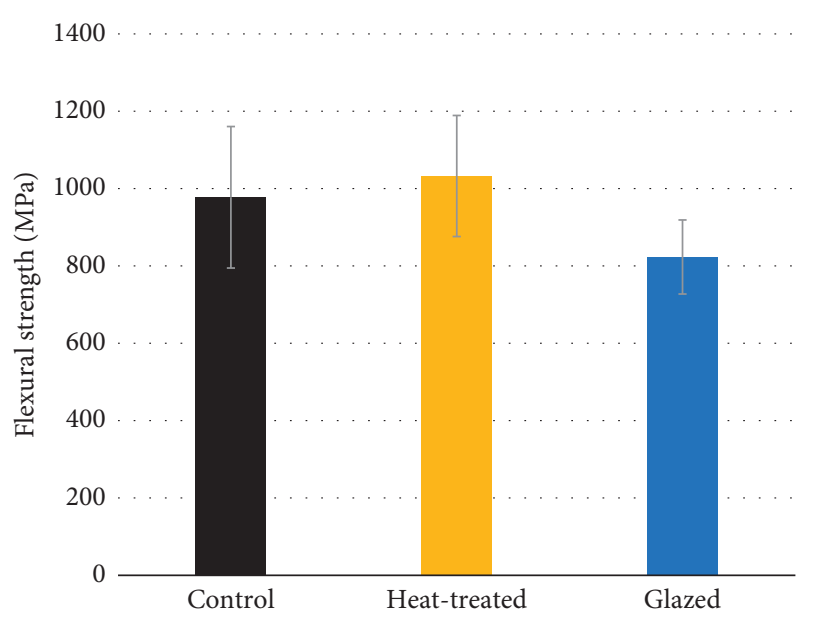

Figure 2: Pooled data from mean flexural strengths of highly translucent zirconia materials with different surface treatments.

reporting that glazing decreased the biaxial flexural strength of Zirkonzahn, Cercon, and Ceramill zirconia.

We conducted this study on heat-treated groups to determine whether the glaze-firing cycle had an effect on the flexural strength of zirconia. We found that there was no significant reduction in the flexural strength of zirconia after being fired with a glazing cycle without glazing materials. The only difference between specimens in this group and 
those in the glazed group was the absence of glaze materials (a mixture of glaze powder and liquid). Therefore, the strength reduction in glazed zirconia found in this study might be due to the glazing.

Residual stresses played an important role in determining the strength of ceramic materials. In cases of residual tensile stress, preexisting stress will amplify the applied cycling stress and induce cracks in that region. Compressive global residual stresses within the ceramic surface can somehow strengthen the material; however, excessive compressive residual stresses can cause lateral cracks to grow and propagate on the surface, and these will eventually cause the material to fail. According to Swain [12], residual stresses can be introduced during the firing process due to thermal expansion mismatch and tempering stresses associated with temperature gradients during cooling.

Due to the metastability of tetragonal zirconia, stressgenerating surface treatments such as grinding or sandblasting are also capable of triggering the $t \rightarrow m$ transformation with the associated volume increase [13]. In this study, we polished all zirconia bars before performing any surface treatment. Therefore, we expected that there would be some $t \rightarrow m$ transformation during this procedure. The coefficient of thermal expansion (CTE) of tetragonal zirconia is approximately $10.5 \times 10^{-6} \cdot \mathrm{K}^{-1}$, while the CTE of monoclinic zirconia is only $7.5 \times 10^{-6} \cdot \mathrm{K}^{-1}$. Therefore, the CTE of polished zirconia might depend on the degree of phase transformation brought about by polishing. The CTE of porcelain was also believed to be changed during firing. Since glazed materials consist of porcelain powder $(\sim 60 \%)$, the CTE change in porcelain might occur in glazed materials during porcelain firing.

Tempering stresses associated with temperature gradients during cooling have also been reported to cause residual stress on ceramics. The poor thermal conductivity of porcelain and zirconia, which is much lower than that of metal alloys, combined with poor thermal diffusivity [14], results in a high temperature difference through the specimens, resulting in high residual tempering stresses and thermal gradients.

The composition of the highly translucent zirconia materials used in this study was different from that of the conventional zirconia designed for coping or a fixed dental prosthesis (FDP) framework. The most notable difference is the reduction or absence of alumina, which is reported to play a significant role in phase stabilization. The effect of residual stresses on the mechanical properties of highly translucent zirconia can be more than that of conventional zirconia. Crown geometry, as is commonly understood, affects residual stress. The scenario of crowns may never be captured in its entirety with the use of simple bar models as a result of their multifaceted geometric properties.

It would be particularly useful in understanding the stress mechanic of this study. Fractographic analysis can give useful information regarding failure origin, failure stress, fracture toughness, and residual stress. Further investigations including fractographic analysis and effect of crown geometry are recommended to complement the present study.

\section{Conclusions}

Within the limitations of the study, the following conclusions can be drawn:

(1) Glazing decreased the flexural strength of the highly translucent zirconia tested $(P<0.05)$.

(2) Glaze firing without the glaze material had no effect on the flexural strength of the highly translucent zirconia tested $(P<0.05)$.

(3) There was no significant difference in the flexural strengths of different brands of the highly translucent zirconia tested $(P>0.05)$.

\section{Disclosure}

The study was presented at the 43rd Annual Meeting of the AADR, Charlotte, NC, in 2014.

\section{Conflicts of Interest}

The authors declare that there are no conflicts of interest regarding the publication of this paper.

\section{References}

[1] M. Albakry, M. Guazzato, and M. V. Swain, "Effect of sandblasting, grinding, polishing and glazing on the flexural strength of two pressable all-ceramic dental materials," Journal of Dentistry, vol. 32, no. 2, pp. 91-99, 2004.

[2] G. Aksoy, H. Polat, M. Polat, and G. Coskun, "Effect of various treatment and glazing (coating) techniques on the roughness and wettability of ceramic dental restorative surfaces," Colloids and Surfaces B: Biointerfaces, vol. 53, no. 2, pp. 254-259, 2006.

[3] H. Shillingburg, Fundamentals of Fixed Prosthodontics, Quintessence Publishing Co., Chicago, IL, USA, 4th edition, 2012.

[4] C. W. Fairhurst, P. E. Lockwood, R. D. Ringle, and W. O. Thompson, "The effect of glaze on porcelain strength," Dental Materials, vol. 8, no. 3, pp. 203-207, 1992.

[5] A. al-Wahadni and D. M. Martin, "Glazing and finishing dental porcelain: a literature review," Journal of the Canadian Dental Association, vol. 64, no. 8, pp. 580-583, 1998.

[6] J. A. Griggs, J. Y. Thompson, and K. J. Anusavice, "Effects of flaw size and auto-glaze treatment on porcelain strength," Journal of Dental Research, vol. 75, no. 6, pp. 1414-1417, 1996.

[7] E. S. Yener, M. Ozcan, and E. Kazazoglu, "The effect of glazing on the biaxial flexural strength of different zirconia core materials," Acta Odontológica Latinoamericana, vol. 24, no. 2, pp. 133-140, 2011.

[8] T. Suzuki, "Relations between translucency and alumina content of dental zirconia," in Proceedings of the Journal of Dental Research in IADR Asia/Pacific Region (APR) Regional Meeting and Co-Annual Scientific Meeting of IADR Divisions, Bangkok, Thailand, August 2013.

[9] R. Ritter, "Use of high translucency zirconia in the aesthetic zone," Dentistry Today, vol. 14, p. 43, 2013.

[10] H. Baharav, B.-Z. Laufer, R. Pilo, and H. S. Cardash, "Effect of glaze thickness on the fracture toughness and hardness of alumina-reinforced porcelain," Journal of Prosthetic Dentistry, vol. 81, no. 5, pp. 515-519, 1999.

[11] K. J. Anusavice, Phillip's Science of Dental Materials, W. B. Saunders, St. Louis, MO, USA, 11th edition, 2003. 
[12] M. V. Swain, "Unstable cracking (chipping) of veneering porcelain on all-ceramic dental crowns and fixed partial dentures," Acta Biomaterialia, vol. 5, no. 5, pp. 1668-1677, 2009.

[13] S. Deville, J. Chevalier, and L. Gremillard, "Influence of surface finish and residual stresses on the ageing sensitivity of biomedical grade zirconia," Biomaterials, vol. 27, no. 10, pp. 2186-2192, 2006.

[14] E. A. Bonfante, B. Rafferty, R. A. Zavanelli et al., "Thermal/mechanical simulation and laboratory fatigue testing of an alternative yttria tetragonal zirconia polycrystal core-veneer all-ceramic layered crown design," European Journal of Oral Sciences, vol. 118, no. 2, pp. 202-209, 2010. 


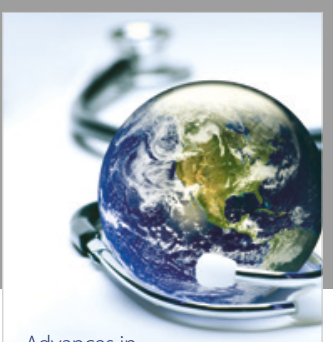

Advances in
Public Health

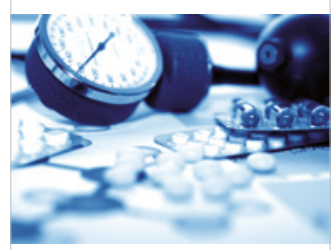

Case Reports in

Medicine

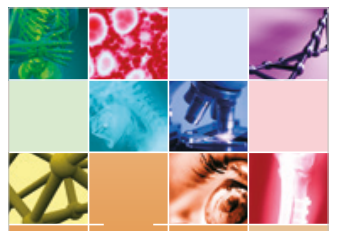

niernational Journal of

Biomaterials
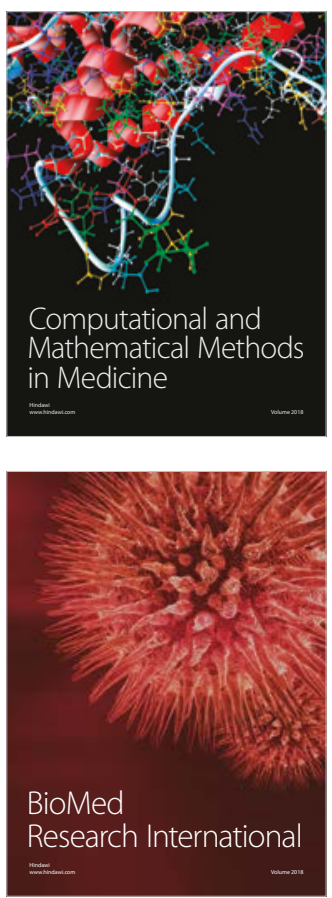

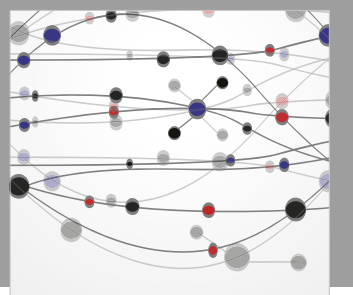

The Scientific World Journal Dentistry

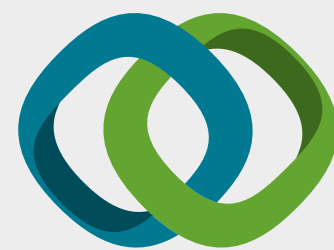

Hindawi

Submit your manuscripts at

www.hindawi.com
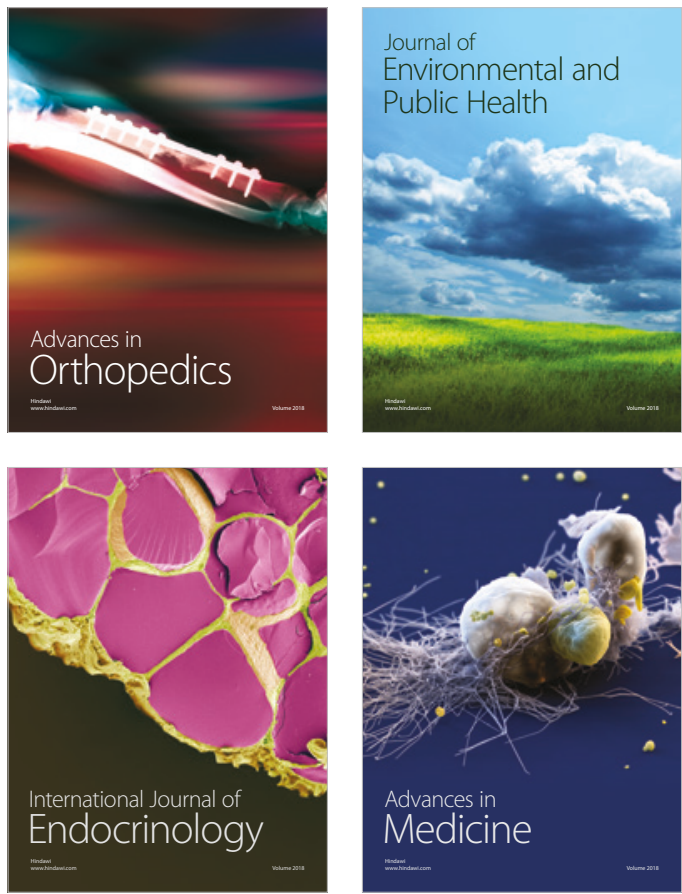
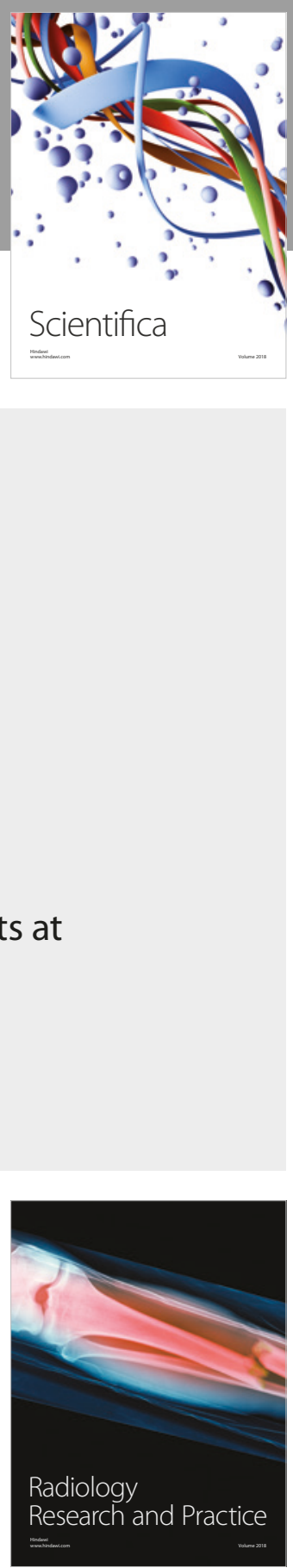

Scientifica

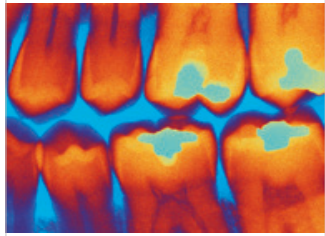

Case Reports in

Dentistry
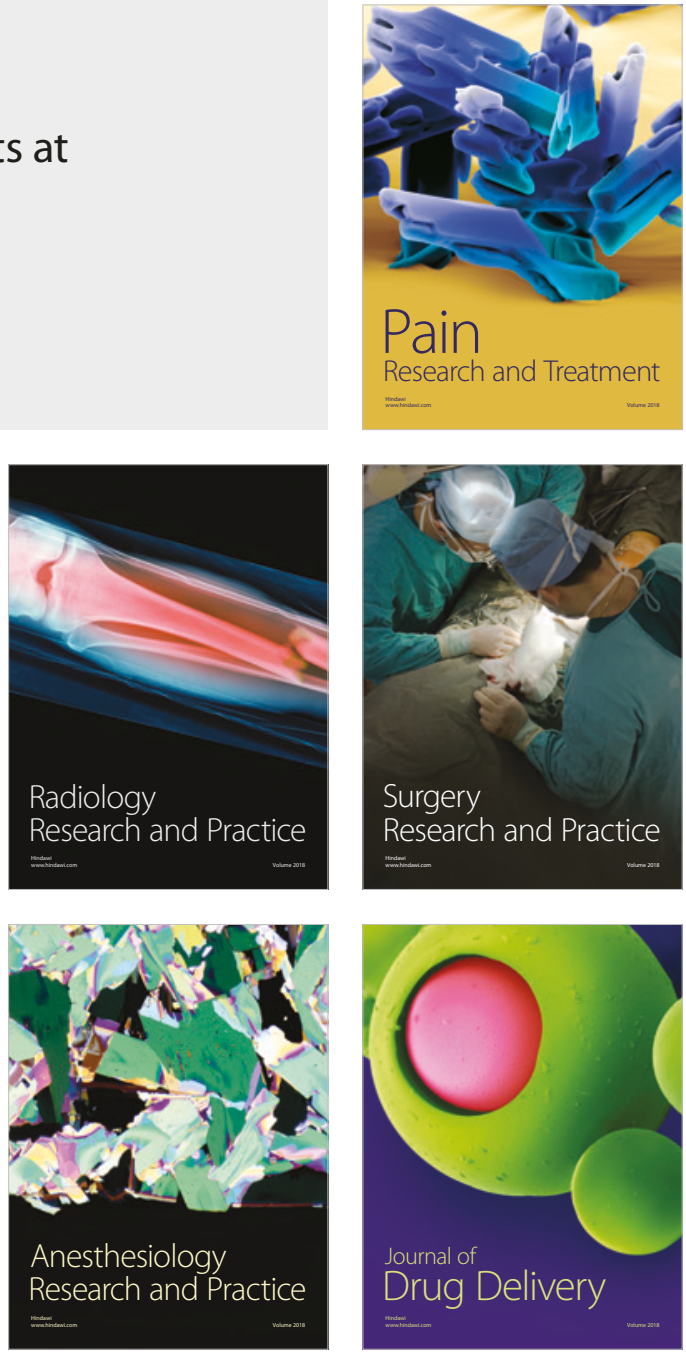